\title{
BOOK REVIEW: Beberapa Tema Reformasi dalam Islam
}

\section{Sahiron Syamsuddin}

\author{
Universitas Islam Negeri Sunan Kalijaga, Yogyakarta
}

\author{
Judul Buku : Der Islam am Wendepunkt: Liberale und \\ konservative Reformer einer Weltreligion \\ Editor : Katajun Amirpur \& Ludwig Ammann \\ Penerbit : Herder, Freiburg, 2006 \\ Halaman : 219
}

Buku yang akan diperkenalkan kepada pembaca ini merupakan kumpulan artikel yang memaparkan secara singkat biografi dan pokokpokok pikiran beberapa pemikir reformis Muslim kontemporer, baik dari kalangan konservatif maupun liberal, dari beberapa negara. Meskipun hanya merupakan preliminary research, buku ini menyajikan informasi-informasi yang sangat menarik dan segar dan tentunya sangat bermanfaat bagi para pembaca yang ingin melakukan penelitian lebih mendalam tentang pemikiran tokoh-tokoh yang disebutkan dalam buku ini. Memuat 19 artikel, buku ini dibagi ke dalam 5 tema besar, yakin (1) wajah Islam di Eropa, (2) konsep demokrasi religius, (3) ruang gerak reformasi syariah, (4) pemahaman rasional tehadap al-Qur'an, dan (5) aktivisme Islam dalam hal pembelaan terhadap hak asasi manusia dan hak kaum wanita. Tema-tema ini ditentukan oleh editor dengan mempertimbangkan tipikal pemikiran tokoh-tokoh yang dipilih. Dalam membahas tema wajah Isam di Eropa, editor menempatkan pemikiran Tariq Ramadan, Soheib Bencheich, Bekir Alboga, Fethullah Güllen dan Abdal-Hakim Murad sebagai contoh. Untuk tema demokrasi religius dipilih tiga pemikir modernis, yakni Mohammed Shabestari, 
Abdul Karim Soroush, Nurcholis Madjid. Ide reformasi syariah, menurut editor, adalah tipikal pemikiran Muhammad Husein Fadlallah, Yusuf al-Qaradawi dan Khaled Abou El Fadl. Untuk tema pemahaman rasional terhadap al-Qur'an dipilihlah Nasr Hamid Abu Zaid, Muhammad Shahrur, Farid Esack dan Mehmet Paçaci. Sementara itu, Gamal al-Banna, Nadia Yassine, Gihan al-Halafawi dan Shirin Ebadi ditempatkan sebagai aktivis-aktivis hak asasi manusia. Pembagian tema-tema tersebut memang terlihat sebagai bentuk simplifikasi, karena beberapa pemikir mempunyai pemikiran-pemikiran yang tidak terfokus pada satu tema tertentu saja. Namun, hal ini suatu kewajaran dalam sebuah buku ontologi semacam ini. Biografi dan model pemikiran masing-masing intelektual tersebut ditulis oleh seorang penulis yang saat ini bertempat tinggal di Jerman. Resensi ini akan memaparkan secara singkat pemikir-pemikir reformis yang telah disebutkan di atas.

\section{Wajah Islam Eropa}

Tariq Ramadan (lahir 1962), cucu pendiri Ikhwan al-Muslimin Hasan al-Banna, yang lama tinggal di Swiss, dipandang oleh sebagian pemerhati keislaman sebagai seorang reformer. Dia mempunyai banyak pengikut dari kalangan muda muslim di kota-kota besar seperti Lyon dan Paris dan dari kalangan intellektual liberal-kiri. Dalam bukunya Les musulmans d'occident et l'avenir de l'islam (2003), dia mengemukakan tiga tipologi pemikiran di dunia Islam, yakni puritanismus, reformismus dan poros tengah antara keduanya. Ramadan sendiri lebih cenderung kepada model pemikiran reformis yang menolak interpretasi literal terhadap teks-teks keagamaan dan memandang perlunya penafsiran rasional, sehingga jiwa teks tersebut tetap dapat dipertahankan, terutama dalam bidang muamalat. Baginya, semua prilaku mu'amalat yang muncul di Eropa dan tidak bertentangan secara jelas dengan Islam tidak hanya harus diterima oleh umat Islam Eropa, tetapi juga harus dipandang sebagai "prilaku islami" per definitionem. Dalam hal ini, Ramadan ingin menegaskan bahwa umat Islam seyogyanya beradaptasi dengan kultur Eropa selama tidak bertentangan dengan prinsip-prinsip Islam. Atas dasar itu, mereka berkewajiban menghormati dan mentaati undang-undang dan peraturan-peraturan yang diberlakukan di Eropa (hlm. 23-33). 
Ide pemahaman Islam inklusif juga dikemukakan oleh Soheib Bencheich, mufti besar kota Marseille Perancis. Di antara pandangan inklusifnya adalah pembolehan pernikahan seorang muslim dengan nonmuslim dan penolakannya terhadap"baduinisasi" (Baduinisierung) atau arabisasi kehidupan umat Islam Perancis. Dia termasuk di antara pemikir yang mengatakan bahwa sumber Islam yang absolut hanyalah al-Qur'an, sementara Sunah Nabi hanya sesuai dengan tradisi dan kultur Arab abad ke-7. "Orang harus hidup di abadnya sendiri," begitulah kata dia. Bencheich juga berpandangan bahwa agar umat Islam menjadi maju, mereka harus banyak belajar dari Barat dan karena itu harus terbentuk hubungan baik antara Islam dan Barat (hlm. 39). Seperti halnya Bencheich, Bekir Alboga (lahir 1963) memandang pentingnya hubungan Islam-Barat, bahkan apa yang disebutnya dengan Solidarit $t$ aller Monotheisten (solidaritas semua umat monotheis).

Untuk menciptakan hal ini, dialog antar kultur menurutnya harus diintensifkan. Dia tidak setuju dengan tesis Huntington yang mengatakan bahwa suatu saat akan terjadi konflik antar kultur. (hlm. 47). Ide dialog antara Islam dan Barat sebelumnya telah dikumandangkan oleh Fethullah Güllen (lahir 1938), pendiri gerakan reformasi pendidikan Islam di Turki. Lebih dari itu, untuk mencapai kehidupan harmonis antara umat Islam dan Barat, dia menggunakan sarana pendidikan yang menggabungkan antara moral Islam dan nilai positif modernitas yang telah berakar di Eropa dan Amerika. Tujuan akhir sistesa kultural ini menurutnya adalah terciptanya "generasi emas" yang bisa memiliki ilmu pengetahuan yang mendalam dan spiritualitas yang kuat (hlm. 56, 59). Dimensi spiritual juga dapat penekanan dari AbdalHakim Murad, seorang bekebangsaan Inggris yang masuk Islam dan sejak tahun 1966 menjadi staf pengajar kajian Islam di Cambridge University.

Meskipun dia bisa dimasukkan sebagai pemikir reformis, namun dia juga sangat kritis terhadap gerakan-gerakan reformis Islam totaliter dan gerakan ortodoksi yang hanya berorientasi pemahaman syariah yang kaku, seperti gerakan Wahhabi, dan juga kritis terhadap gerakan Islam libral. Dia lebih cenderung kepada gerakan yang menampung keberagaman tradisi keislaman, termasuk di dalamnya tradisi sufi. Menurutnya, Islam mempunyai dua dimesi: dimensi lahiriah dan 
dimensi batiniah. Kedua dimensi ini telah ditunjukkan oleh Nabi Muhammad sendiri. Dengan kesadaran akan keberagaman tradisi Islam, menurutnya, Islam dapat berakulturasi dengan tradisi dan kultur lokal ('urf) manapun. Atas dasar ini, tugas generasi muda muslim adalah berupaya memperlihatkan bahwa Islam juga bisa memperluas potensi tradisionalnya dalam berakulturasi dengan kultur Barat, selama kultur tersebut tidak jelas-jelas bertentangan dengan ajaran al-Qur'an dan Sunnah Nabi (hlm. 64-71).

\section{Konsep Demokrasi Religius}

Berkaitan dengan tema konsep demokrasi religius, buku ini menampilkan tiga pemikir. Mohammad M. Shabestari (lahir 1936), seorang teolog Syiah berkebangsaan Iran, dalam ceramah-ceramah dan tulisan-tulisannya selalu mengemukakan perlunnya perhatian terhadap kebebasan berpendapat, demokrasi dan hak-hak asasi manusia. Kesemuanya ini dipaparkannya dengan perspektif teologis dan filosofis. Di satu sisi, dia tetap mengacu pada tradisi keilmuan Islam rasional, yakni tradisi Mu'tazilah, dan spiritualisme sufistik. Di sisi lain, teoriteori hermeneutika Barat diaplikasikannya juga dalam memahami alQur'an dan Sunnah Nabi, khususnya yang berkaitan dengan masalahmasalah muamalah. Selain itu, filsafat Immanuel Kant dan teologi Protestan mendapat perhatian yang cukup signifikan dalam mengelaborasi tema kebebesan manusia. (hlm. 75-76).

Tokoh Iran lain yang juga concerned dalam penegakan demokrasi adalah Muhammad Soroush. Dia berusaha membangun demokrasi di Iran yang disebutnya dengan "demokrasi religius" yang merupakan respons terhadap sistem politik ala velayat-e faqih. Menurutnya, demokrasi merupakan buah dari pemikiran manusia yang didasarkan atas pemahaman-pemahaman rasional yang memuat nilai keadilan dan konsep-konsep hak asasi manusia. Karena itu, nilai-nilai demokratis harus diejawantahkan oleh umat Islam dalam menjalankan pemerintahan. Sistem politik tirani, baginya, bertentangan dengan hakikat dan martabat kemanusiaan. Lebih lanjut, dia menegaskan bahwa demokrasi tidak berarti memisahkan agama dari dunia poltik. Demokrasi justru dapat menjaga eksistensi dan ruang gerak agama. Umat dan lembaga-lembaga keagamaan seyogyanya terpanggil untuk 
terlibat dalam diskursus-diskursus politik, sehingga nilai-nilai religius dapat mempengaruhi gerak dan langkah manusia dalam berpolitik. Meskipun demikian, pandangan-pandangan keagamaan tidak boleh didikte oleh Negara dan tidak boleh dilaksanakan dengan cara pemaksaan. Nilai-nilai keagaman harus diperjuangkan dan dibawa oleh masyarakat sendiri dalam diskursus-diskursus politik dan sosial (hlm. 82-90). Di Indonesia, ide demokrasi diusung, antara lain, oleh Nurcholish Madjid. Dia menolak upaya-upaya yang mengarah pada pendirian negara Islam Indonesia. Negara Indonesia yang didasarkan pada Pancasila telah cukup memberikan wadah untuk pelaksanaan aktivitas keagamaan. Meskipun demikian, prinsip-prnsip agama, tegasnya, harus diperjuangkan secara demokratis agar roda pemerintahan di Indonesia tetap disinari oleh semangat spiritiualisme religius yang kuat (hlm. 96)

\section{Ruang Gerak Reformasi Syari‘ah}

Reformasi hukum Islam tidak luput dari perhatian para pemikir muslim kontemporer. Muhammad Husain Fadlallah (lahir 1935), seorang tokoh di Libanon, misalnya, melakukan pembaruan dalam bidang ushul fiqh. Dia mencoba memahami sumber-sumber keagamaan, yakni al-Qur'an dan Sunnah Nabi, tidak secara dogmatis. Dalam hal ini, Fadlallah tidak berangkat dari kedua sumber agama Islam tersebut dan mengambil ajaran-ajaran agama yang abstrak untuk diterapkan ke dalam kehidupan sehari-hari (teks suci à manusia), namun dia membaca dan menafsirkan keduanya dengan memperhatikan terlebih dahulu kehidupan manusia (manusia à teks à manusia). Hukum agama, menurutnya, dapat berubah sesuai dengan perubahan situasi dan kondisi dalam kehidupan manusia. (hlm. 100-101). Reformasi hukum juga dilakukan oleh Yusuf al-Qaradawi (lahir 1926), seorang alim yang mempunyai banyak pngikut dari berbagai negara, dengan ungkapannya: "Semua yang tidak dilarang secara tegas dalam al-Qur'an dan Sunnah adalah mubah". Hal ini membuka lebar-lebar ruang gerak penafsiran dan pembaruan hukum. Senada dengan Fadlallah, Qaradawi menegaskan bahwa hukum harus diperbarui, ketika waktu, tempat dan kondisi kehidupan manusia berubah. Karena lebih menekankan pada kehidupan manusia, pemikiran-pemikiran hukum Qaradawi dikenal 
dengan istilah fiqh al-waqi“ (fiqih realitas kehidupan).

Hal ini berarti bahwa dalam rangka pembaruan hukum pada masa kini seorang pemikir muslim tidak cukup hanya mengenal al-Qur'an dan Sunnah, tetapi juga kehidupan kontemporer (hlm. 112-113). Kehidupan kontemporer mendapatkan perhatian dalam pemikiran Islam Khaled Abou El Fadl (lahir 1963), seorang pemikir Mesir yang hidup di Amerika. Dia adalah salah seorang penentang pemahaman puritan yang tidak santun terhadap kaum wanita dan umat minoritas dan yang menggunakan strategi kekerasan dalam menyelesaikan masalah hidup. Menurutnya, strategi kekerasan tidaklah berasal dari pemikiran Islam klasik, melainkan bersumber dari ideologi pembebasan yang muncul pasca kolonial pada abad ke-19 dan ke-20. Karena itu, saat ini Aboul Fadl mengajak umat Islam untuk kembali ke Syariah Islam yang sebenarnya santun terhadap kepentingan kaum wanita dan minoritas serta tidak dengan cara kekerasan (hlm. 121-122).

\section{Pemahaman Rasional terhadap al-Qur'an}

Tema yang juga menjadi sorotan para reformis kontemporer adalah bagaimana al-Qur'an seharusnya diinterpretasikan pada masa sekarang ini. Nasr Hamid Abu Zaid (lahir 1948), seorang ahli hermeneutika al-Qur'an, mengemukakan bahwa al-Qur'an selain sebagai kitab keagamaan, sebaiknya dipandang juga sebagai karya sastra seperti karya-karya sastra yang lainnya, sehingga ia bisa didekati, dianalisis, dan ditafsirkan dengan berbagai macam pendekatan. Abu Zaid sendiri melakukan pembacaan terhadap teks al-Qur'an dengan pendekatan ilmu sastra, hermeneutika, dan semiotika. Semuanya ini dimaksudkan untuk menguak makna historis teks al-Qur'an, karena ia berhubungan erat dengan situasi dan kondisi bangsa Arab saat ia diwahyukan oleh Allah kepada Nabi Muhammad. Bersamaan dengan pencarian makna historis, seorang penafsir juga harus mampu menguak makna di balik makna literal teks, yang disebutnya dengan istilah maghza (signifikansi). Setelah itu, tugas seorang mufassir adalah menerjemahkan dan mengaktualisasikan signikansi ini untuk diterapkan pada situasi dan kondisi saat ini (hlm. 130-132). Tafsir historis semacam ini diikuti pula oleh seorang sarjana al-Qur'an dari Turki, yakni Mehmet Paçaci, yang terpengaruh oleh paradigma hermeneutik double movement ("gerakan 
ganda") Fazlur Rahman dan teori hermeneutik historisches Bewusstsein ("kesadaran sejarah") Hans George Gadamer (hlm. 158-162).

Meskipun demikian, baik Abu Zaid dan Paçaci tidak mengingkari adanya pluralitas penafsiran yang disebabkan oleh kepentingan penafsir. Pluralitas penafsiran juga ditekankan oleh Muhammad Shahrur (lahir 1938), di samping sebagai sebuah realita interpretatif, juga sebagai pemicu bahwa setiap generasi muslim berhak dan dituntut untuk selalu menafsirkan al-Qur'an sesuai dengan perkembangan zaman dan ilmu pengetahuan. Berbeda dengan Abu Zaid, Shahrur memandang bahwa seorang penafsir tidak perlu menguak makna historis ayat al-Qur'an, karena dia berpegang pada paradigma: “Teks al-Qur'an itu tetap, namun isi kandungannya terus berkembang." Selain itu, Shahrur juga berpandangan bahwa penafsiran, sebagaimana halnya alam semesta, tunduk terhadap hukum berproses: suatu saat dia berada pada posisi "berada" (kaynuna), namun pada saat yang lain ia berada pada posisi "menjadi" (sayrura). Hal ini berarti bahwa penafsiran pasti terus mengalami perkembangan dan selalu bersifat relatif dan subyektif. Atas dasar ini, umat Islam modern, menurutnya, berhak atau bahkan seharusnya menafsirkannya dengan pola pikir kemodernan dan sesuai dengan kondisi sosial dan saintifik saat ini. Kebenaran penafsiran, tegasnya, ditentukan apakah ia dapat memberikan kemasalahatan untuk memecahkan problem-problem kontemporer (hlm. 139-140). Di antara problem kontemporer yang misalnya dihadapi oleh Afrika Selatan beberapa tahun yang lalu adalah problem apartheid. Dalam rangka berpartisipasi dalam mengatasi problem tersebut, Farid Esack menggunakan kemampuannya dalam bidang penafsiran al-Qur'an, khususnya ayat-ayat al-Qur'an yang memuat "teologi pembebasan" dan pluralisme. Baginya, usaha ini dapat menghimpun berbagai kekuatan yang ada di masyarakat dalam rangka mengatasi problem penindasan penguasa saat itu. Singkat kata, Esack berusaha menjadikan al-Qur'an sebagai salam satu solusi terhadap masalah sosial (hlm. 149-153).

\section{Aktivisme Islam untuk Hak-hak Asasi Manusia}

Perjuangan atas hak-hak asasi manusia tidak luput dari perhatian para reformis. Gamal al-Banna dalam tulisan-tulisannya kerap sekali memperjuangkan hak kaum wanita. Dia berargumentasi bahwa Allah 
tidaklah membedakan antara lelaki dan wanita. Di dalam al-Qur'an disebutkan bahwa baik lelaki maupun wanita diciptakan oleh Allah dari satu nafs (jiwa). Al-Qur'an juga menyebutkan kaum wanita beriman beriringan dengan lelaki beriman. Kaum wanita disebutkan pula sebagai saudari kaum lelaki. Nabi sendiri adalah sosok yang penuh hormat terhadap kaum wanita. Ini semua menunjukkan, tegas al-Banna, bahwa Islam memandang wanita dan lelaki sederajat. Hal yang membedakan hanyalah tingkat ketakwaan masing-masing. Karena itu, al-Banna menghimbau umat Islam secara keseluruhan untuk tidak melakukan kekerasan dan penekanan terhadap kaum wanita. (hlm. 165-68). Hakhak kaum wanita diperjuangkan juga oleh Nadia Yassine (lahir 1958), juru bicara gerakan al-adl wa-l-iḥsān Maroko. Dia melanjutkan citacita ayahnya, Abdessalam Yassine, yang juga pendiri gerakan tersebut, yakni "modernisasi Islam" dan "islamisasi modern". Reformasi Islam bagi dia tidak cukup dengan kata-kata saja, melainkan yang terpenting dengan aksi. Nabi Muhammad dipandangnya sebagai contoh feminis di masanya. Beliau melakukan perbaikan situasi dan kondisi kaum wanita pada abad ke-7 M. Atas dasar itu, Yassine sutuju atas pemberlakuan syariah Islam di masa modern dengan catatan adanya pembaruan interpretasi terhadapnya (hlm. 173, 180).

Aksi untuk perjuangan kaum wanita sempat dicoba oleh Gihan al-Halafawi dengan cara mendaftarkan diri pada tahun 2000 sebagai kandidat wanita untuk anggota parlemen Mesir dari Ikhwan alMuslimin, sebuah organisasi Islam konservatif di Mesir. Meskipun dia bukan seorang pemikir ulung, namanya sempat menjadi buah bibir, khususnya di negaranya dan di negara-negara Arab pada umumnya. Keputusannya untuk menjadi kandidat anggota parlemen dimotivasi oleh niatnya untuk memperbaiki nasib dan derajat kaum wanita di Mesir melalui peningkatan pendidikan dan pemberdayaan kaum wanita dalam berbagai bidang kehidupan sosial. Di dalam wawancaranya dia mengatakan: "Tidak ada satu ayatpun dalam al-Qur'an yang melarang kaum wanita untuk berperan serta dalam bidang politik." Selain itu, dia mengemukakan peran Khadijah dan A'isyah dalam bidang sosial dan politik pada masa awal Islam. Meskipun akhirnya dia tidak terpilih sebagai anggota parlemen, Gihan al-Halafawi merupakan simbol pembaharu di lingkungan Islam konservatif (hlm. 182, 184 dan 187). 
Di Iran, Shirin Ebadi (lahir 1947), seorang pemikir dan aktivis kemanusiaan, selalu memperjuangkan hak-hak asasi manusia, terutama hak-hak kaum wanita dalam berbagai bidang. Perjuangannya ini disemangati oleh pemahaman Islam yang progresif. Dia termasuk orang yang gigih menolak prilaku diskriminatif yang diatasnamakan agama, sebagaimana yang terjadi di negaranya. Pada saat dia menerima nobel perdamaian pada tanggal 10 Desember 2003, dia mengatakan: "Diskriminasi terhadap kaum wanita tidak mempunyai dasar di dalam al-Qur'an." Diperlakukannya kaum wanita saat ini secara tidak adil di banyak negara Islam tidaklah didasarkan atas ajaran al-Qur'an, melainkan bahwa sampai saat ini penafsiran al-Qur'an didominasi oleh kaum lelaki yang hanya ingin mengambil keuntungan darinya. Dia menegaskan: "Islam tidak mempunyai hubungan sama sekali dengan penindasan terhadap kaum wanita. Islam mengandung keyakinan akan keadilan dan persamaan.” Ebadi juga mengatakan bahwa Islam tidak bertentangan dengan hak-hak asasi manusia dan demokrasi. Pembelaannya terhadap hak-hak asasi manusia mendorongnya untuk selalu bersikap kritis, bukan hanya terhadap kebijakan-kebijakan negara-negara Islam, tetapi juga terhadap prilaku politik dalam dan luar negeri negara-negara Barat. Dia tidak segan-segan menentang kebijakan politik luar negeri Amerika Serikat yang dipandangnya menodai nilai-nilai kemanusiaan (hlm. 190-198).

Demikianlah kira-kira yang bisa disarikan dari buku tersebut. Penulis resensi berharap agar ada di antara pembaca yang tertarik melakukan penelitian lanjutan tentang pemikiran salah seorang (atau lebih) dari para pemikir yang telah disebutkan di atas, karena artikelartikel yang terdapat di dalam buku ini masih perlu dikembangkan lagi meski dengan pendekatan yang sama. Akan lebih baik lagi apabila penelitian yang akan datang menggunakan pendekatan yang lebih komprehensif. Selain itu, diharapkan juga adanya penelitian lain tentang tema-tema reformasi Islam yang berkaitan dengan aspek ekonomi dan perkembangan sains dan teknologi yang lepas dari perhatian buku tersebut di atas. 